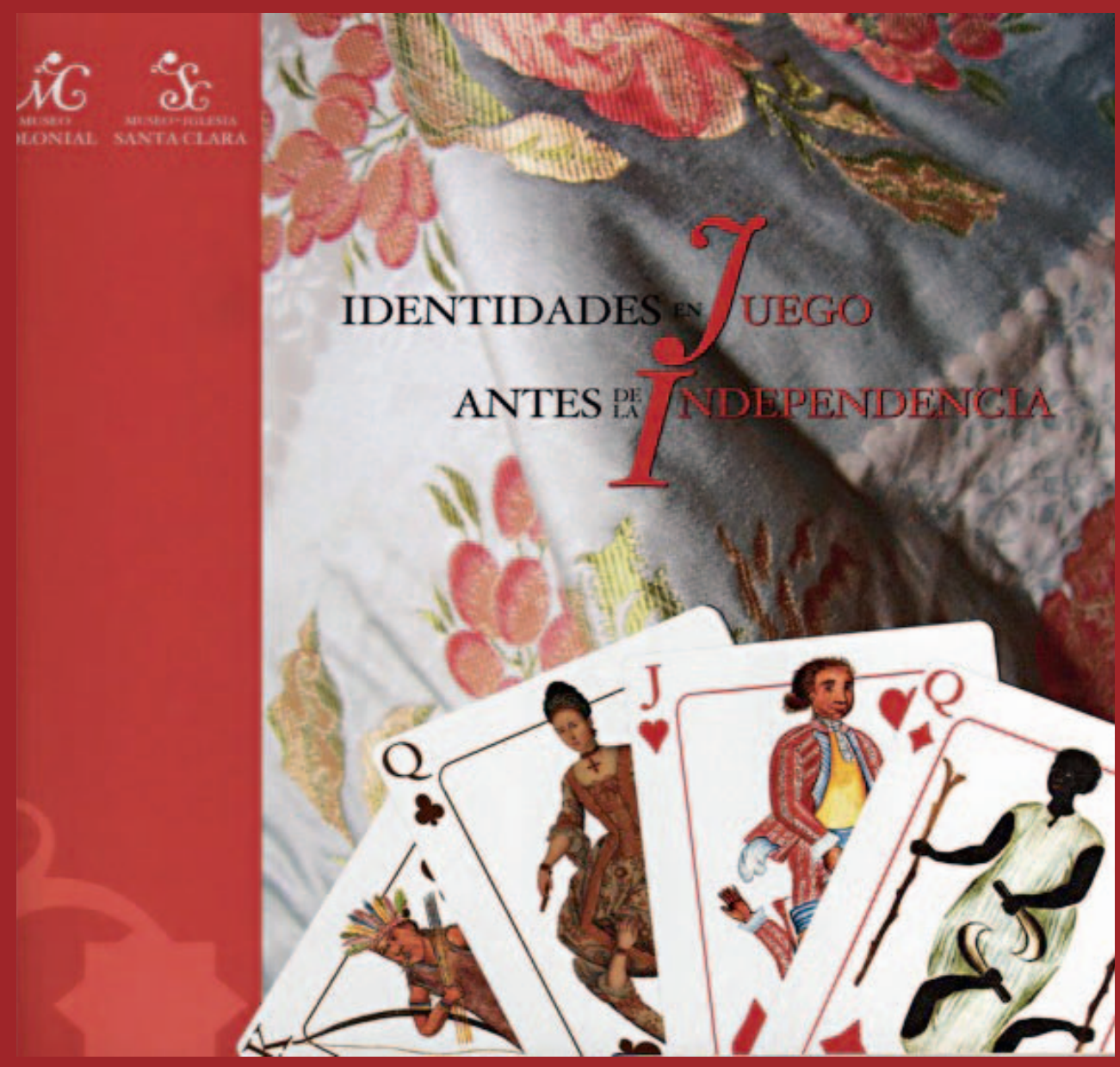

Fig.1. Carátula de Catálogo de la exposición. Bogotá: Ministerio de Cultura. 2010. 


\section{Museología

\author{
Identidades en juego antes de la \\ Independencia. Caso de estudio: \\ Exposición Nueva Sala Permanente \\ del Museo Colonial, Bogotá
}

Kelly Carpio Ochoa

\section{Introducción}

En el 2010, Colombia conmemoró el Bicentenario de su independencia. Durante ese año varias instituciones, organizaciones y comunidades académicas se concentraron en dicho acontecimiento, tanto en su celebración como en su crítica. Los museos no fueron ajenos a esta dinámica y organizaron con antelación proyectos museológicos: exposiciones, seminarios, conferencias, visitas guiadas, talleres, entre otros, que se presentaron en diferentes ciudades de Colombia. En Bogotá, los proyectos expositivos de los museos del Ministerio de Cultura, a saber: Museo Nacional de Colombia, Museo Casa del Florero -ahora Museo de la Independencia- y el Museo Colonial, recibieron críticas y suscitaron interrogantes sobre el abordaje curatorial y museográfico con el que se acercaron al acontecimiento fundacional de la nación colombiana.

Es así que la Maestría en Museología y Gestión del Patrimonio de la Universidad Nacional de Colombia, al tener como meta la instauración de la disciplina museológica en el país, y la crítica museológica profesional como uno de sus componentes, en colaboración con los museos del Ministerio de Cultura en Bogotá, y el Sistema de Patrimonio Cultural y Museos de la Universidad Nacional de Colombia, organizó en sus Sesiones abiertas 2011, el Seminario independencia en el museo? Consensos y disensos sobre las exposiciones conmemorativas del Bicentenario de la Independencia de los museos del Ministerio de Cultura en Bogotá.

La sesiones abiertas de la Maestría en Museología, como espacio de reflexión pública sobre los museos colombianos, permitieron compartir en este seminario un espacio de discusión sobre las repercusiones de la representación museográfica que conmemoró el Bicentenario en los espacios oficiales en Bogotá. Este artículo es el resultado de la ponencia que se presentó el día 16 de marzo del 2011 en la sesión correspondiente del Seminario dedicada al Museo Colonial (Fig.1).

Caso de estudio: sala permanente museo colonial

Antes de proceder con este caso de estudio, quisiera señalar que las exposiciones se han convertido en un fenómeno sociocultural insustituible entre las actividades habituales de los museos. Constituyen -tanto para las instituciones museales como para otras entidades análogas con o sin fines de lucro como fundaciones, casas de cultura, galerías comerciales, ferias, entre otras- un instrumento indispensable de presentación, interpretación, difusión de colecciones y de objetos de interés patrimonial así como un espacio para la divulgación de conocimientos y objetivos de las instituciones (Fernández, 1999:10). 
La actividad expositiva, como función de los museos al servicio de la comunidad, resulta cada vez más atrayente y demandada por los diferentes públicos. Esta actividad puede ser de carácter permanente o no. De acuerdo con la nueva museología:

La exposición es uno de los más importantes útiles de diálogo y concienciación de que dispone el museólogo, un método de trabajo esencial de acercamiento y diálogo con la comunidad dentro de la responsabilidad que les incumbe al museólogo y al museo de estudiar, preservar y difundir su patrimonio (Fernández, 1999:10).

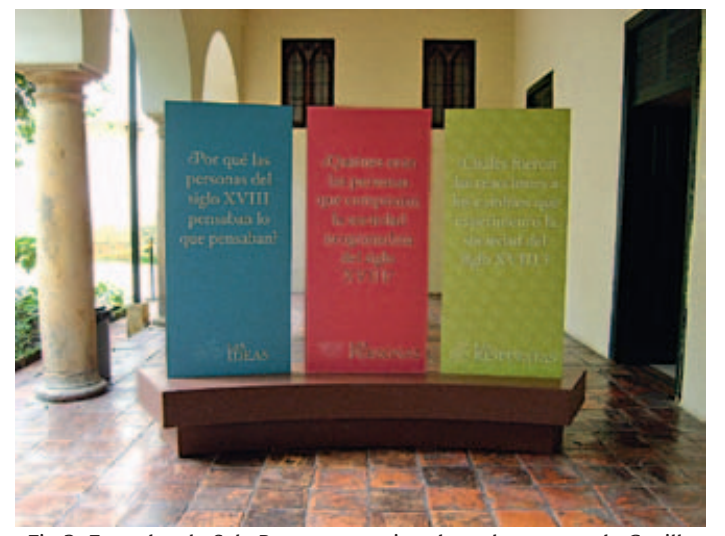

Fig.2. Entrada a la Sala Permanente situada en la restaurada Capilla de Indios.

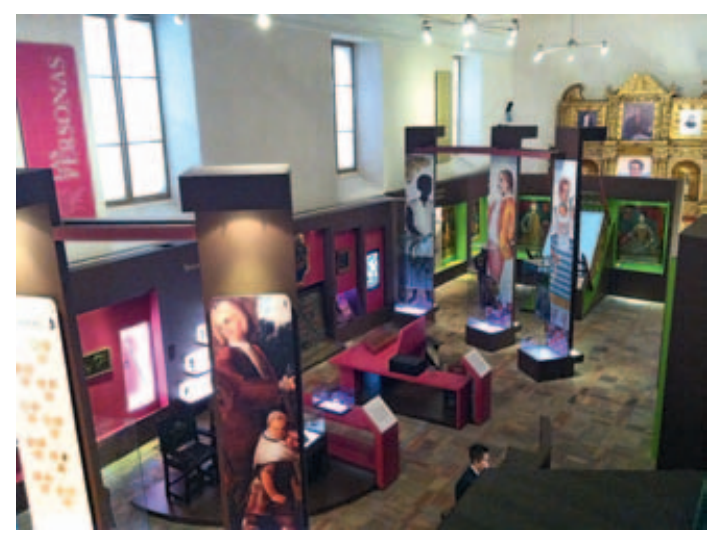

Fig.3. Vista general de la Sala. Tema 2: Las personas.

Museológicamente -nos explica Fernández- una exposición tiene un fuerte componente interpretativo: es mostrar y relatar; es decir, consiste en una puesta en escena de objetos interpretados con los que se quiere contar y comunicar un relato $(1999: 16)$. Por ello, las exposiciones son un complejo sistema de conceptualización, interpretación, diseño, organización, referencia y comunicación, todo esto en un mismo tiempo y espacio, entre otras posibilidades. Así mismo, las exposiciones presentan, representan y hasta dramatizan hechos, historias, mensajes o ideas que se quiere resaltar y transmitir. El acto de seleccionar un objeto y yuxtaponerlo o contraponerlo con otros, está lejos de ser un capricho, pues comporta profundas implicaciones que afectan al observador de diversas maneras.

Las principales características de las exposiciones son las siguientes ${ }^{1}$ :

Valor cultural: la exposición exhibe algo digno de mostrarse ante diferentes públicos por su valor cultural. Los objetos que integran la exposición son interesantes porque se destacan entre los demás de su tipo.

Mostrar claramente: Por ser de carácter público, los objetos y los conocimientos deben mostrarse lo más claramente posible. Los visitantes deben apreciar los objetos sin obstáculos visuales. Además, los conocimientos, textos e ideas deben ser sencillos y entendibles con facilidad.

Se relacionan lógicamente: Los objetos y las ideas expuestas deben relacionarse entre sí siguiendo cierta lógica: por autor, por tema, por material, por composición narrativa, por técnica, por procedencia, por fecha, por complementariedad, entre otros.

Tienen una cualidad tridimensional: las exposiciones adquieren especial relieve al facilitar el encuentro entre los objetos y los públicos; permiten la visión del objeto en su totalidad

1 La explicación de las tres primeras características se toman del texto de López, 1993:13. 
y hacen posible tener una experiencia multisensorial no sólo de los objetos sino también del conjunto de la exposición, moviéndose dentro y alrededor de ella.

Estas características deben contribuir al enriquecimiento intelectual y cultural de los públicos. En la medida en que una exposición goce de una organizada planeación, un claro guión científico y museográfico, una buena selección de objetos, una buena documentación y un buen montaje, el objetivo de la exposición será claramente positivo y realizable.

A continuación, anoto algunas características de las exposiciones temporales. La diversidad de temas expuestos hace que los diferentes públicos del museo vean siempre algo nuevo al mismo tiempo que se motiva a los no públicos. Los temas a tratar deben ser consecuentes con el discurso museológico de la institución. Las exposiciones temporales se renuevan y complementan con distintos temas y objetos de la exposición permanente. Adicionalmente, ofrecen la oportunidad ideal para ser innovadoras y atrevidas sin afrontar

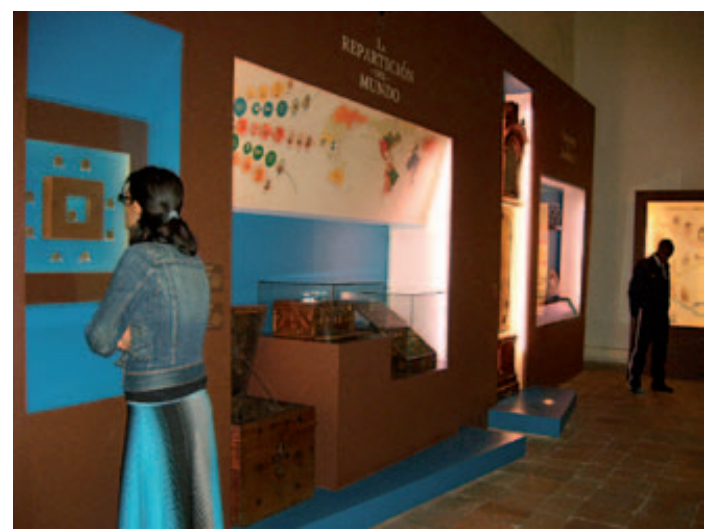

Fig.4. Mobiliario museográfico
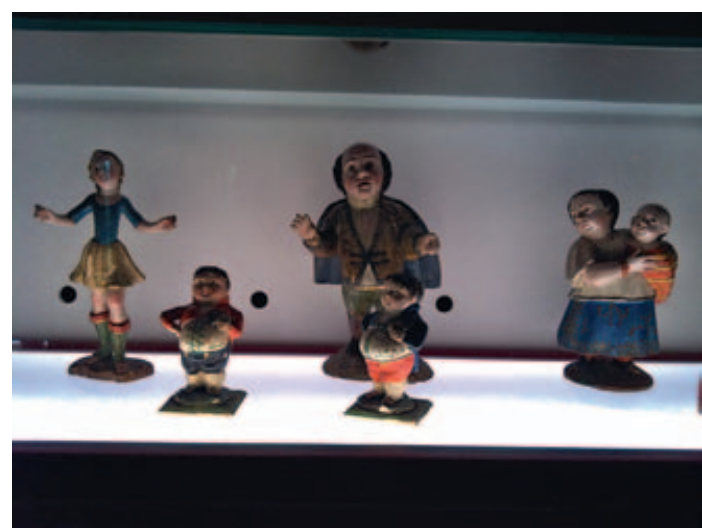

Fig.5. Figuras de pesebre s. XVIII sobre cajas de luz

muchos riesgos. Se pueden intentar nuevas formas de presentación museográfica-que no afecten la materialidad de los objetos- y que más adelante se puedan implementar en la exposición permanente: nuevos enfoques, nuevas técnicas. Por ejemplo: una nueva disposición de los objetos y del mobiliario expositivo, nuevos sistemas de iluminación, redacción de textos, dispositivos educativos e interactivos, nuevas tecnologías, recorridos, entre otros.

Belcher destaca un aspecto importante de las cualidades de las exposiciones temporales:

Su capacidad de ser actual y controvertida. A través del uso de unas estructuras adecuadas y la inclusión del material disponible (aunque sea exclusivamente gráfico), un museo puede dar respuesta casi espontáneamente (si tienen los suficientes recursos) a sucesos de la vida cotidiana. Es ésta una capacidad muy importante si el museo quiere promover una imagen de estar al día, preocupado por el presente, el pasado y el futuro (1997:64).

Ahora bien, de cara al caso que nos ocupa, puedo decir que la Nueva Sala Permanente del Museo Colonial se ajusta a estas pautas. Cabría preguntarse, si esta sala será un referente para la implementación de las siguientes nuevas salas que están previstas en el Plan Museológico de esta institución.

Las pautas museográficas para el análisis de este primer Caso de Estudio se estructuran siguiendo el guión descrito en Pautas para la implementación del Trabajo de Grado 20072009, publicación proporcionada por la Maestría y que contempla los siguientes puntos: 
1. Carácter de la exposición, 2. La Exposición, 3. Ámbitos y Unidades de representación, 4. Estrategias de comunicación en la sala y 5 . Consideraciones finales.

\section{PAUTAS MUSEOGRÁFICAS DE LA EXPOSICIÓN}

Paso a detallar los criterios evaluativos museográficos de este caso:

\section{Carácter de la exposición}

- Título: Identidades en juego antes de la Independencia. El enunciado del título logra situarnos en una temporalidad específica y las imágenes que lo ilustran señalan inequívocamente varios de sus protagonistas: indígenas, criollos, mestizos y afrodescendientes.

- Tema: La confluencia de culturas indígenas, mestizas y colonizadas con las de los afro descendientes esclavizados bajo el poder hispano en el s. XVIII. Esta convergencia produjo una cultura híbrida que prefiguró la silueta del criollo, protagonista de la Independencia. La Nueva Sala en la recién restaurada Iglesia de los Indios, da cuenta de este siglo de transformaciones (Toquica, 2010: 17-18).

- Objetivo: Representar los procesos culturales del siglo XVIII que forjaron la creación de identidades en el Nuevo Reino de Granada, generando en el visitante una reflexión sobre el presente a partir de la pregunta: ¿Quién es usted? (Toquica, 2010: 20). Si bien, la puesta en escena de los procesos de un siglo de transformaciones políticas, económicas, científicas y culturales son temas muy amplios, creo que no se llega a acometer de modo suficiente la pregunta objetivo de la muestra por la amplitud de los temas expuestos: ¿Quiénes somos?

\section{La Exposición}

- Tramas Discursivas: La investigación curatorial se estructuró a partir de tres ejes:

¿Por qué las personas del siglo XVIII pensaban lo que pensaban? - Las ideas

¿Quiénes eran las personas que componían la sociedad neogranadina del siglo XVIII? - Las personas

¿Cuáles fueron las reacciones a los cambios que experimentó la sociedad del siglo XVIII? Las respuestas (Fig.2).

- El Posicionamiento del objeto: Los objetos en la exposición priman y fueron puestos para que comuniquen las ideas a tratar. Se ha hecho una muy buena selección de objetos procedentes de diferentes colecciones institucionales. Sin embargo, la ubicación de los mismos en la sala generan la impresión de un espacio recargado o atiborrado que no obedece a un

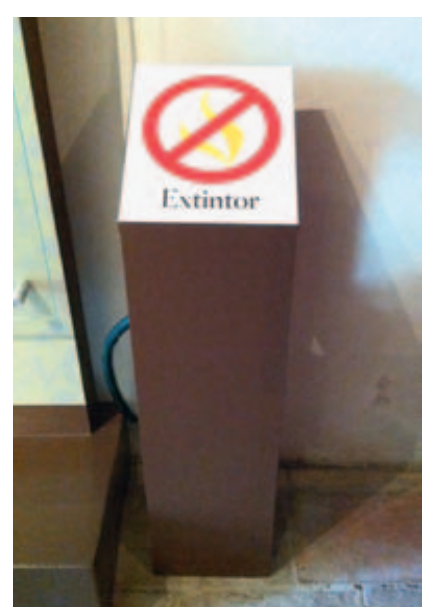

Fig.6. Extintor “camuflado" ordenamiento, por lo menos, a primera vista.

- Mobiliario museográfico: El mobiliario museográfico se muestra macizo y pesado. Está ubicado alrededor de toda la sala y da la idea de una falsa pared, es decir, es envolvente. Asimismo, éste se dispone en tres grupos centrales a lo largo de la sala. Por ello, el mobiliario ocupa todo el espacio, lo achica, compitiendo en algunos casos con las piezas (los grupos centrales no dejan ver una panorámica de la sala), por ejemplo: las piezas-mueble que se encuentran en los extremos: el dosel de la puerta y el retablo; y la cama de estilo virreinal) (Fig.3).

- La Sala: se encuentra ubicada en lo que fue la Iglesia de los Indios, que ya de por sí tiene un valor patrimonial y una memoria arquitectónica. En el catálogo se habla de las obras de intervención en este espacio que tuvo como objetivo la restauración de la Iglesia. Uno de los puntos 
de la restauración fue la recuperación del piso original hecho de arcilla que, como anotaba, el mobiliario museográfico no deja apreciar esta intervención arquitectónica; en consecuencia, el mobiliario compite con el espacio patrimonial (Fig.4).

- Iluminación: está dada por: Iluminación artificial (lámparas incandescentes en el techo del recinto; luz halógena puntual y luz indirecta de las cajas de luz en el mobiliario museográfico); y, la luz natural de las ventanas. A mi juicio, la luz ambiental se ve escasa debido al control de deterioro para las piezas sensibles y con policromía. Por otra parte, las cajas de luz del mobiliario en unos casos tienen muy buen resultado, como en el bastón de mando pero, en otros no, como es el caso de las figuras del pesebre dispuestas en el ámbito 2; la luz desde abajo no deja ver el color ni las técnicas de estofado características del s. XVIII. Pienso que se habría podido jugar más con la iluminación en la base del mobiliario para evitar tropezar con éste (Fig.5).

- Seguridad: se cuenta con el apoyo del personal de vigilancia. La sala cumple con los requisitos de seguridad industrial: señalización en casos de emergencia y señalización de las rutas de acceso y vías de escape. Igualmente, se dispone de extintores para casos de incendio ubicados en lugares estratégicos y muy bien "camuflados". Estos son los pequeños detalles que muchas veces olvidamos al momento de disponer la sala y hacer el montaje (Fig.6).

- Conservación: el equipo del museo siempre cuenta con un personal especializado en conservación, por ello, no

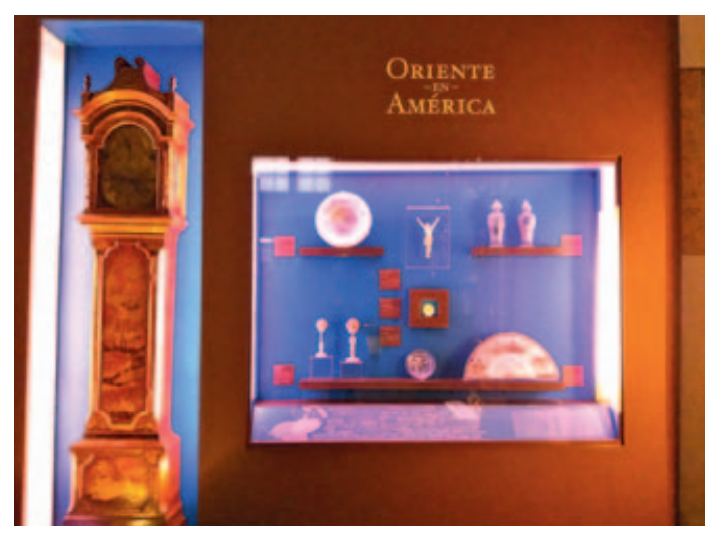

Fig.7. Iluminación con filtro y soportes.

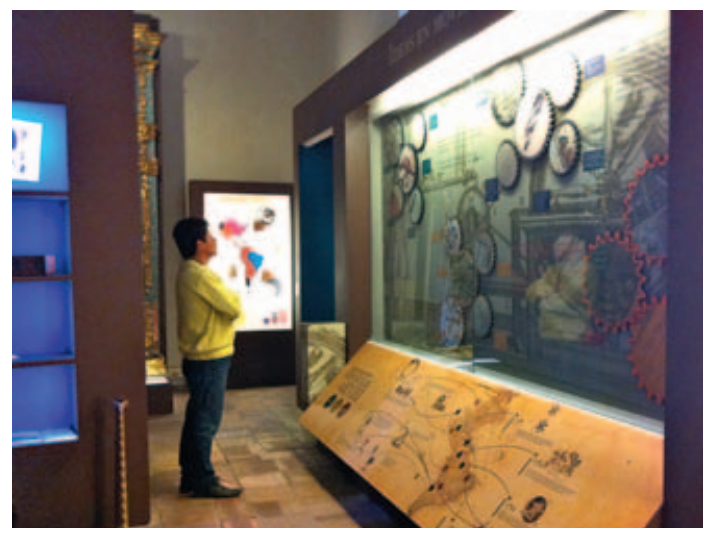

Fig.8. Poco espacio entre el mobiliarios museográficos.

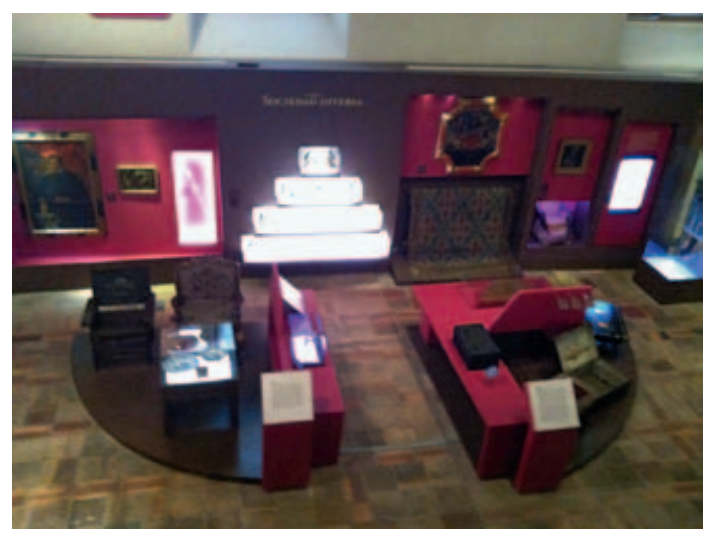

Fig.9. Vista parcial con distribución de muebles en el centro de la sala.

escatima esfuerzos para la conservación preventiva tanto de la sala como de las piezas expuestas. Las condiciones de deterioro están controladas y estabilizadas por deshumificadores, dataloggers y termómetros dispuestos estratégicamente en la sala. El control de luz natural está dado por filtros en las ventanas, y el de la luz artificial por filtros en las cajas de luz del mobiliario o luz indirecta y halógena para textiles, tallas y lienzos con policromía. Así mismo, cada una de las piezas que lo necesite tiene un soporte hecho especialmente y permite observarla con detalle (Fig.7). 
infografías o proyecciones. En el módulo central, hay una banca disimulada que permite al visitante tomar un descanso para "reflexionar" y observar el conjunto de la sala (Figs 8 , 9 y 9a).

La pregunta que me asalta es: ¿cómo están atendiendo a los grupos escolares o de visitantes de 20 personas o más?, ¿cómo han abordado y solucionado este problema?

\section{3. Ámbitos y unidades de representación}

La exposición está dividida en tres grandes unidades de representación:

- ¿Qué pensaban las personas del s. XVIII? - Las Ideas

Se ayuda con proyecciones y medios interactivos, muy bien elaborados y que llaman la atención, como "el ingreso a la universidad". Las infografías: "Oriente en América” y "Cuerpo y Medicina”, entre otras, son una gran ayuda pedagógica que puede ser impresa y repartida en visitas escolares. Los mapas de repartición y exploraciones científicas de éste ámbito son muy acertados, salvo algunos detalles como la falta de dirección de las rutas comerciales entre Europa y sus colonias. La escenificación del gabinete de curiosidades, tiene un lugar importante pero hace falta un texto de apoyo que brinde más información sobre el tema (Fig.10).

\section{- ¿Quiénes componían la sociedad neogranadina del siglo XVIII? - Las personas}

Se destacan los paneles horizontales dispuestos como tótems en el centro de la sala y los diagramas simplificados de las "pinturas de castas" que nos muestran el producto de la mezcla de razas que existía en el Nuevo Mundo. Estas pinturas están relacionadas a las castas de la Nueva España (hoy México). Me pregunto: ¿no hubo suficiente investigación histórica para tener imágenes de pinturas de la Nueva Granada? En todo caso, es necesario escribir la referencia (Fig.11).

- ¿Cómo reaccionó la sociedad del s. XVIII a los cambios, políticos, culturales, religiosos y económicos? - Las respuestas

Una de las piezas centrales y que resalta en este ámbito, es una cama puesta en un ángulo poco usual simbolizando la limpieza de sangre y el mestizaje; es una apuesta museográfica atrevida y novedosa donde el objeto también se convierte en soporte. Y, la otra, es el retablo de los protagonistas de la Independencia que es despojada de su función religiosa original en la Capilla de Indios, para transformarla en soporte y mueble escenográfico del "altar de la patria" (Figs. 12 y 13$)$.

\section{Estrategias de Comunicación en la Sala de exposición}

Como se explica, el relato de la exposición se dejó a una comunicación

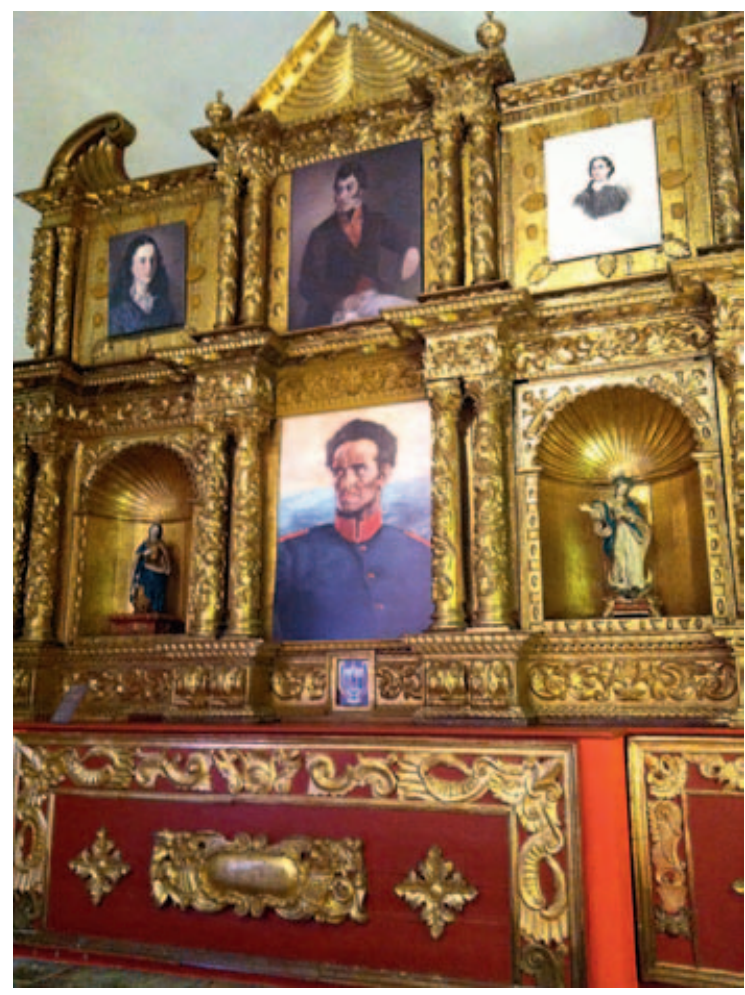

Fig.13. Retablo con imágenes religiosas y reproducciones de próceres de la Independencia colombiana: Policarpa Salavarrieta, José Antonio Galán, Antonia Santos y Antonio Nariño. 


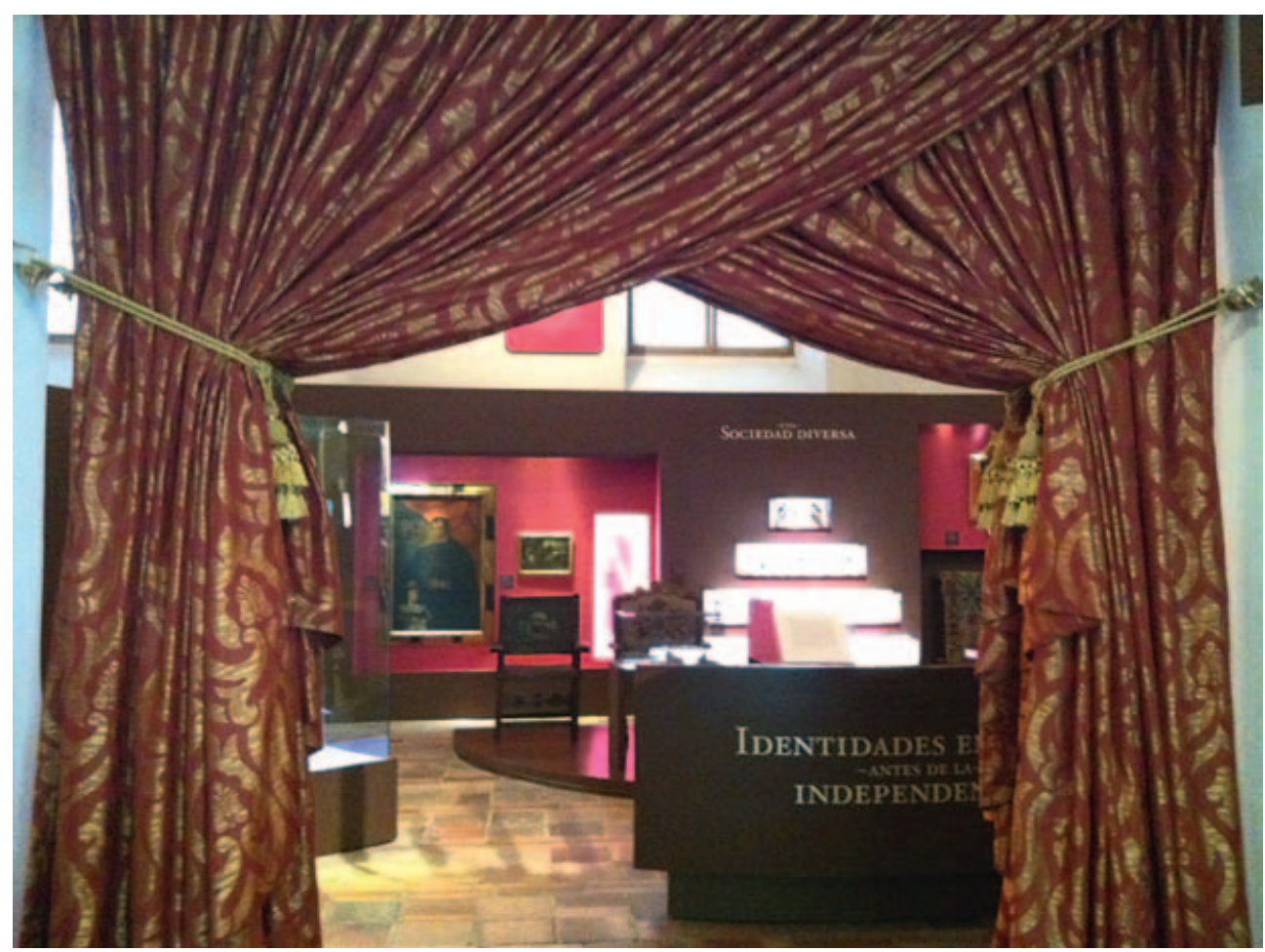

Fig.14. Cortinaje que da entrada a la sala

visual y simbólica; por ello, no hay textos que indiquen o expliquen cada uno de los ámbitos o textos que acompañan al visitante en el recorrido de la exposición. Es una gran apuesta dejar todo el trabajo de interpretación al visitante. En ese ejercicio se cuenta con la dificultad de recordar las tres preguntas de la entrada a la sala. El pasadizo de bienvenida a la sala, donde se encuentra la introducción y los créditos, nos sugiere que detrás del ostentoso cortinaje entraremos a un gran salón. Los colores predominantes de este espacio intermedio (rojos y dorados) simbolizan la élite neogranadina del siglo XVIII, y se relacionan con la corte y retratos de los virreyes. Al entrar a la sala hay una disparidad cromática: está llena de luces, objetos y colores (Fig.14).

También, dentro de esta apuesta de comunicación visual, está la utilización de colores fuertes que reflejan el "el espíritu del s. XVIII"; colores utilizados en paneles y nichos (azul, rojo y verde) para identificar los tres ámbitos. Estos se emplean como fondos de vitrinas para dar contraste pero, compiten con los objetos (Fig.15).

Las cartelas que señalizan las unidades de representación se encuentran muy altas y, a primera vista, uno no las advierte (Fig.16).

Me pregunto si se logra que el visitante haga el ejercicio o experiencia visual para interpretar y entender el mensaje propuesto por el equipo curatorial del museo, como es el caso de "los zapatos bellamente elaborados contrastados con la imagen de una persona descalza, que pretende ilustrar la disparidad entre los miembros de diferentes grupos sociales"; estos objetos tienden a relacionarse por complementariedad y pueden confundir al visitante. Igualmente, la escenografía: "Clasificar la obra de Dios", del gabinete de curiosidades, es muy buena pero, ¿̇realmente logra construir el mundo que rodea al criollo, mestizo, indígena y afro descendiente del siglo XVIII; es un mapa de su cotidianidad, como reza en el catálogo? (Figs.17a y 17b). 


\section{VIVA EL REY, MAL GOBIERNO}

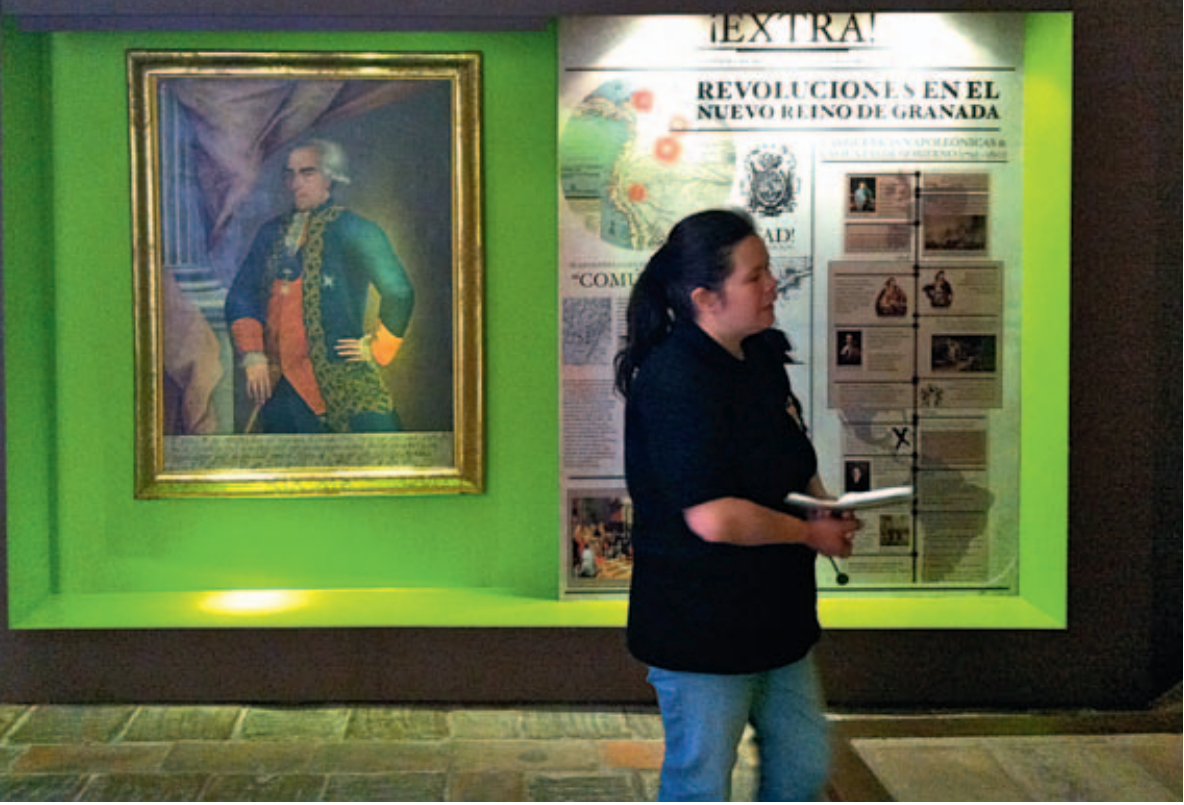

Fig.15. Colores de fondo

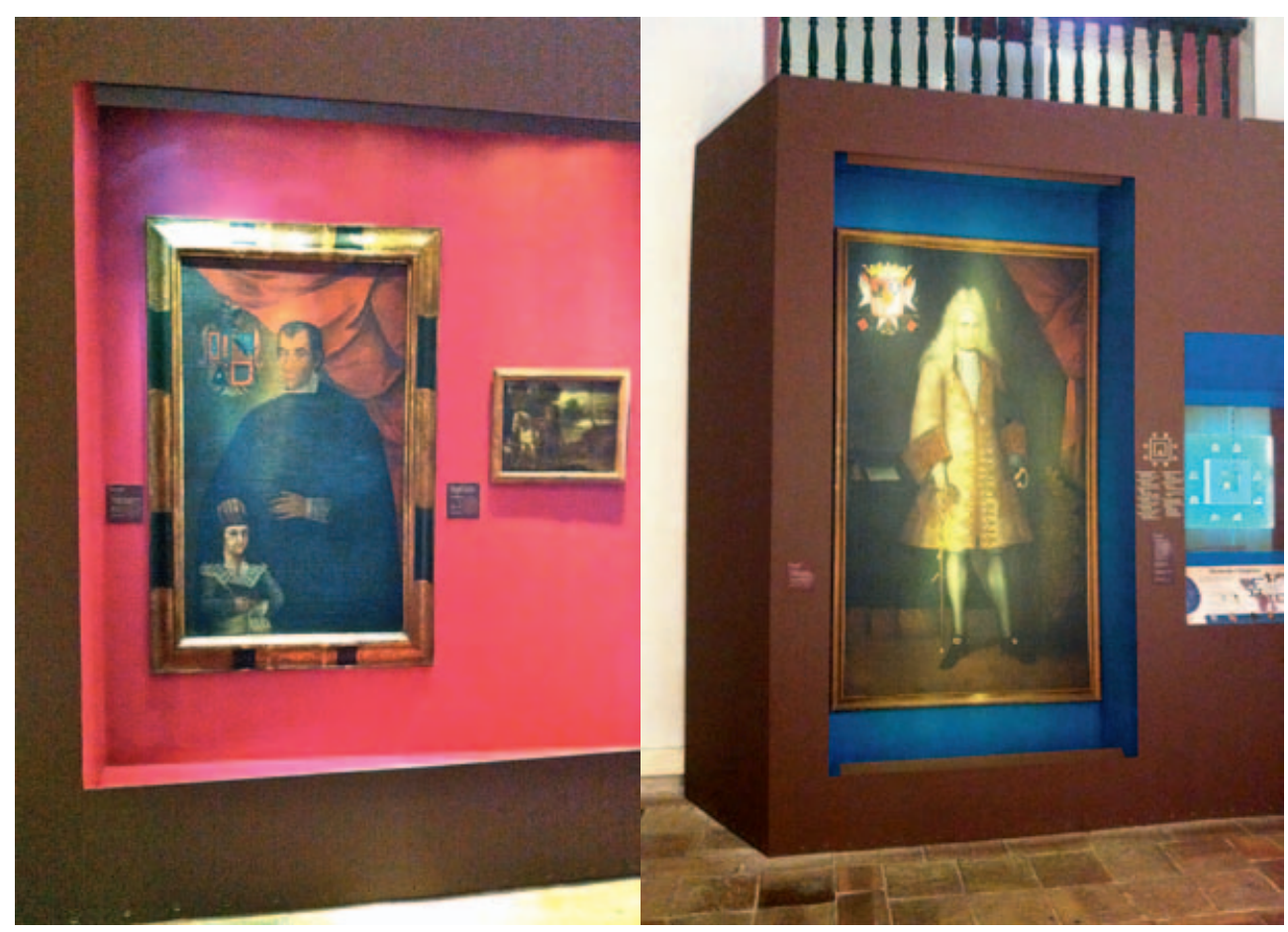


Fig.16. Cartelas temáticas

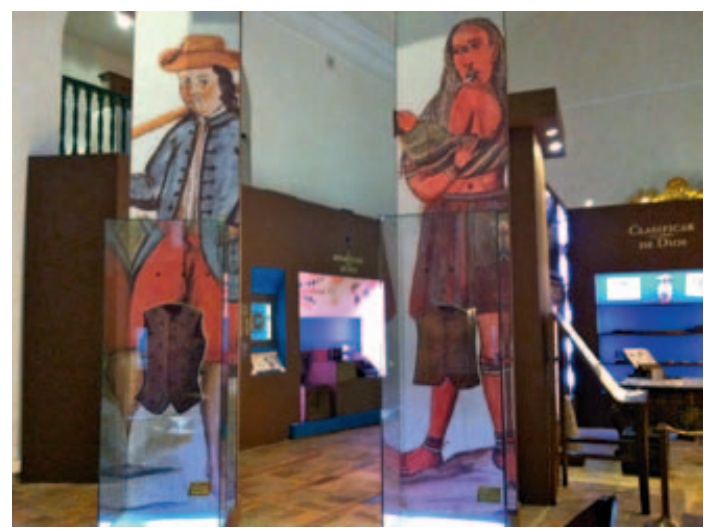

Fig.17a. Contraste de imágenes y objetos

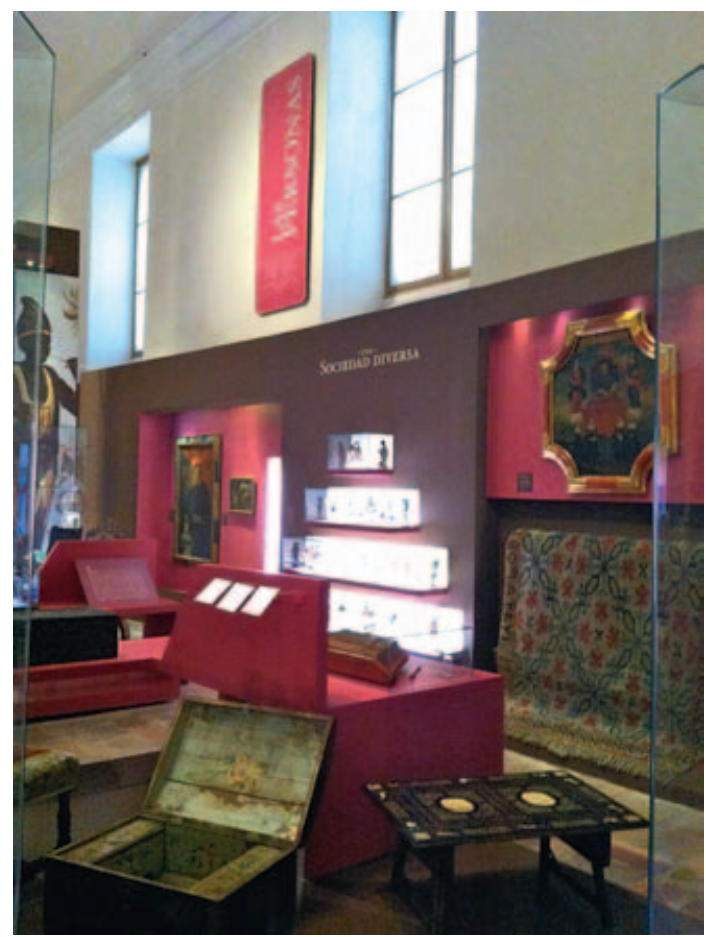

\section{Consideraciones finales}

Es de singular importancia compartir -entre otras- la tesis de Barry Lord y Gail Dexter (2002) según la que, en una exposición, el aprendizaje es prioritariamente afectivo. Según los autores, la exposición de un museo no es eficaz para comunicar información muy compleja o transferir conocimiento. Los museos -al modo de los medios de comunicación de masas- son excelentes en la generación de entusiasmo, en desafiar opiniones sostenidas por largo tiempo, en despertar intereses, en incitar una toma de conciencia de asuntos específicos $\mathrm{y}$, en generar profundas respuestas emocionales o reforzar las que ya se tienen. En virtud del seguimiento de estos lineamientos, esta exposición no pretende exigir de los visitantes una gran retención de datos; antes bien, se encaminó a despertar un interés por las identidades en juego en el siglo XVIII, "momentos antes" de la Independencia.

Si bien, una bitácora forma parte de un estudio de públicos, sería bueno saber si el Museo Colonial realizará o está realizando una evaluación sumativa en la cual pregunte a sus visitantes específicamente por la nueva sala en sus aspectos: comunicativos, informativos y simbólicos, entre otros. Esta evaluación respondería a las siguientes preguntas:

¿Quién visita la exposición y cómo se apropia de ella? ¿Tuvo el visitante una experiencia significativa y/o de disfrute?; y ¿la exposición cumplió con los objetivos propuestos? Su sistematización suministrará información esencial para el manejo y dirección de todo el museo; responderá a la inquietud de saber si la exposición es exitosa; descubrirá errores y hará recomendaciones para intervenciones futuras. Por eso, la evaluación tiene que ser considerada como una parte necesaria de todo nuevo desarrollo de exposiciones, particularmente, de la renovación de las exposiciones permanentes ayudando así a la configuración y guión de las siguientes salas del Museo Colonial.

Felicito a Constanza Toquica, Directora del Museo Colonial y del Museo-Iglesia Santa Clara, así como al equipo curatorial del museo integrado por profesionales de distintas disciplinas, por haber acometido el desafío que supuso esta audaz apuesta de un nuevo concepto museológico y museográfico de re-presentación del patrimonio histórico de 
la nación colombiana. La finalidad de esta crítica es abrir un debate desde la profesión museológica que permita fortalecer y respaldar nuevos conceptos e ideas de futuras exposiciones en Colombia.

Finalmente, quisiera volver a preguntar con la exposición: ¿qué pensaban, quiénes eran, cómo reaccionaron en el convulsionado s. XVIII las culturas indígenas, mestizas y afro esclavizadas?; y nosotros, como habitantes del s. XXI, ¿quiénes somos y qué herencia conservamos y promovemos de ellos?

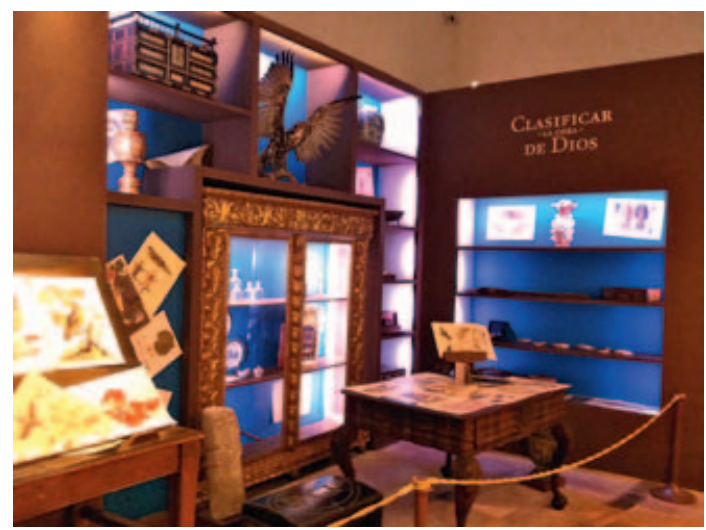

Fig.17b. Gabinete de curiosidades "Clasificar la obra de Dios".

\section{Referencias}

BALLART, Josep

(2007) Manual de Museos. Madrid: Editorial Síntesis.

BELCHER, Michael

(1997) Organización y diseño de exposiciones. Su relación con el museo. Gijón: Ediciones Trea.

CARPIO OCHOA, Kelly

(2008) Estudios de visitantes y evaluación de exposiciones: Perspectiva británica. Bogotá: Maestría en Museología y Gestión del Patrimonio-UNAL. Trabajo final presentado para el módulo "Taller de Tesis II". 28 de noviembre.

(2008a) Curadurías, Nuevas miradas del arte peruano. Bogotá: Maestría en Museología y Gestión del Patrimonio - UNAL. Trabajo final presentado para el módulo "Administración de Colecciones II". 21 de mayo de 2008.

CASTRILLÓN, Alfonso

(1986) Museo peruano: utopía y realidad. Lima: Editorial gráfica, $138 \mathrm{pp}$.

FERNÁNDEZ, Luis Alonso

(1999) Introducción a la nueva museología. Madrid: Alianza Editorial, 208 pp.

(1995) Museología: Introducción a la teoría y práctica del museo. Editorial Istmo, Madrid, $424 \mathrm{pp}$.

FERNÁNDEZ, Luis Alonso e Isabel GARCÍA FERNÁNDEZ

(2007) Diseño de exposiciones. Concepto, instalación y montaje. Madrid: Alianza Editorial, 267 pp.

HERNÁNDEZ, Francisca

(2006) Planteamientos teóricos de la museología. Gijón: Ediciones Trea, 287 pp.

LORD, Barry y Gail DEXTER

(2002) The Manual of Museum Exhibitions. London: Altamira, 544 pp.

LÓPEZ BARBOZA, Fernando

(1993) Manual de Montaje de exposiciones. Bogotá: Colcultura.

http://www.museocolonial.gov.co/index. php?idcategoria $=39316$ 